\title{
ERRATUM
}

\section{The absorption, metabolism and excretion of flavan-3-ols and procyanidins following the ingestion of a grape seed extract by rats}

By Catherine Tsang, Cyril Auger, William Mullen, Aurélie Bornet, Jean-Max Rouanet, Alan Crozier and Pierre-Louis Teissedre

Volume 94 (2005) Number 2

Page 175

In error, the incorrect figure 3 was inadvertently published. The correct version can be found below and online at http://www. ingentaconnect.com/content/cabi/bjn
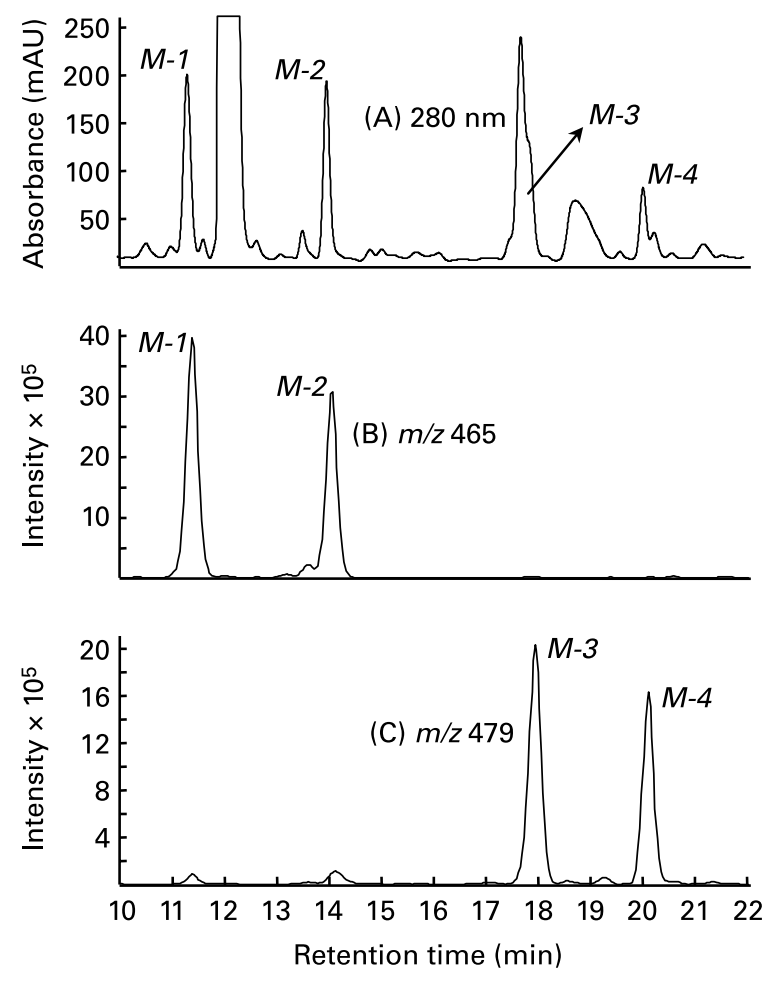

Fig. 3. Reversed-phase HPLC analysis, with diode array and MS-selected ion monitoring detection, of the flavan-3-ol metabolites $(+)$-catechin glucuronide $(M-1),(-)$-epicatechin glucuronide $(M-2)$, methyl- $(+)$-catechin glucuronide $(M-3)$, methyl-(-)-epicatechin glucuronide $(M-4)$ in rat plasma collected $4 \mathrm{~h}$ after the ingestion of a grape seed extract. Extract analysed using a $60 \mathrm{~min} 5-40 \%$ gradient of acetonitrile in $1 \%$ aqueous formic acid with detection at $280 \mathrm{~nm}(\mathrm{~A}), m / z 465(\mathrm{~B})$ and $m / z 479$ (C). For $\mathrm{MS}^{2}$ data, see Table 2. 